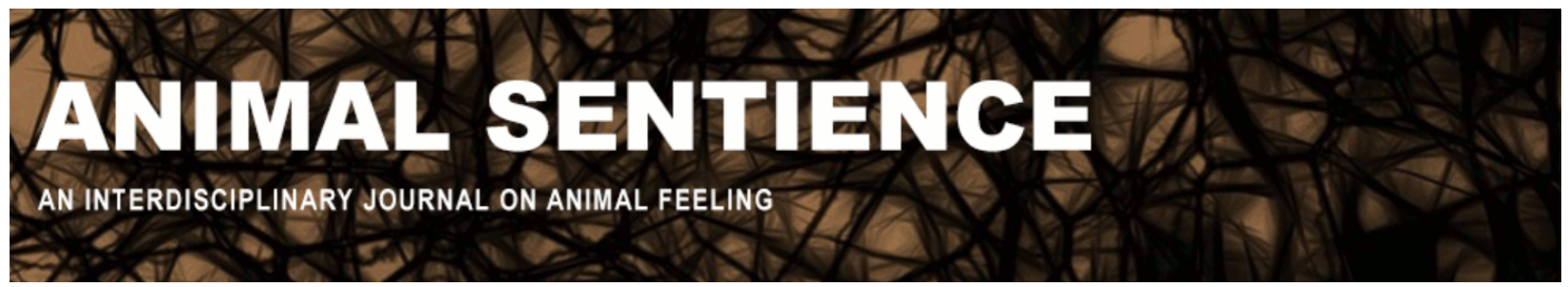

Thys, Tierney M (2020) Exploring eight-armed intelligence through film. Animal Sentience 26(27)

DOI: $10.51291 / 2377-7478.1658$

Date of submission: $2020-11-05$

Date of acceptance: $2020-12-28$

(c) (†)

This article has appeared in the journal Animal

Sentience, a peer-reviewed journal on animal

cognition and feeling. It has been made open access,

free for all, by WellBeing International and deposited

in the WBI Studies Repository. For more information,

please contact

wbisr-info@wellbeingintl.org.

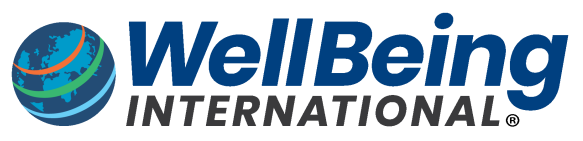

SOLUTIONS FOR PEOPLE, ANIMALS AND ENVIRONMENT 


\title{
Exploring eight-armed intelligence through film
}

\author{
Commentary on Mather on Octopus Mind
}

\author{
Tierney Thys \\ Research Associate Dept of Ichthyology, \\ California Academy of Sciences
}

\begin{abstract}
Mather (2019) provides a rich overview of the elements underlying octopus cognition and behavioral flexibility. Recently, two remarkable natural history films, $M y$ Octopus Teacher and The Octopus in My House have explored intimate human-octopus relationships with a wild (Octopus vulgaris) and a captive octopus (Octopus cyanea) respectively. Both films show rare behaviors that offer observations to test new hypotheses as well as a novel perspective on our own human relationships and place within the natural world. An interview with filmmaker Craig Foster from My Octopus Teacher reveals the profound and transformative power of forming a trusting relationship with such a cognitively capable yet evolutionarily distant group of animals.
\end{abstract}

Tierney Thys is Research Associate at California Academy of Science, biologist, filmmaker and National Geographic Explorer. Current research includes: mapping connections between nature imagery and human wellbeing with Stanford University and University of Utah; satellite tracking marine megafauna in South America and; reducing plastic pollution. Website

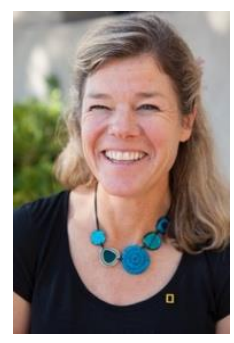

A duo of remarkable natural history films, My Octopus Teacher ${ }^{1}$ and Octopus in My House ${ }^{2}$, have recently explored the development of two intimate human-octopus relationships-one with a wild octopus and the other with a captive one. Both films reveal rarely witnessed behaviors and have received awards for their content, storytelling and cinematography.

Mather's (2019) target article provides a rich overview and experimental context for understanding octopus cognitive and behavioral flexibility. The present commentary, based on an interview with Craig Foster, the filmmaker of My Octopus Teacher, adds to the ongoing discussion on the Octopus mind, highlighting two provocative case studies in which humans are able to build trust and nurture curiosity with two different species of octopuses, making powerful personal discoveries about themselves along the way.

My Octopus Teacher shows Craig Foster on a journey of self-exploration. Over the course of a year, Foster re-establishes the bond he had lost with the sea when he lived in his childhood coastal home on the Atlantic Ocean off South Africa. Each day, without a wetsuit, he free-dives into the kelp forest up to two hours in water temperatures that can drop as low as $8^{\circ} \mathrm{C}$. During this cold-water immersion, he finds solace in teaching himself what he calls wild language, a form of underwater tracking where:

"each tiny track, bite mark, egg case ... are the letters of this language. The words are when these letters point to which species made them. Then when you can see the behaviors in the tracks, these are the first basic sentences that start to form the language. Eventually, and only sometimes, these sentences form this magnificent wild language and you see into the secret world of extraordinary creatures. These moments of grace are very precious. Anyone

\footnotetext{
${ }^{1}$ My Octopus Teacher is a Netflix Original film, produced in partnership with the Sea Change Project by Off the Fence and ZDF Enterprises.

${ }^{2}$ The Octopus in My House is Passion Pictures Films for BBC, distributed by PBS in the USA under a different title, Octopus: Making Contact.
} 
can do this, it just requires lots of dedicated time, lots of curiosity and photographing and writing masses of notes."

Along the way, Foster meets a remarkable individual, a female common octopus, Octopus vulgaris, with whom he develops a strong relationship built on mutual curiosity. As trust grows between them, the octopus becomes increasingly comfortable leaving her den and wrapping herself around Foster's hands. At one point, she allows him to carry her to the surface where he can refill his lungs with air. Eventually, she allows him to accompany her on hunting forays and even appears to enjoy cuddling up on his bare chest. He has obviously won her trust. These intimate experiences dramatically alter Foster's views of octopuses:

"The shear surprise of being trusted by a cephalopod had a profound effect on me. Then to be let into her world and have a sense of her strategies, her genius, her way of dealing with predators. . It can't be compared to being seen by a human for me. One might expect a human to teach you things, but I never expected to be taught by an octopus. . . to be taught how she deals with so many prey species, to be let inside her den and to discover a new species of crustacean living with her, Heteromysis octopodis. It gave me a sense of my own wildness, but also a sense of how little I knew of the wild world, and fueled my deep desire to study and learn from animals, to learn from science, and to keep diving every day.

Being with the octopus in her native habitat with such regularity, broadens Foster's views on octopus intelligence. He admits that

"before making this film, I realized they [the octopuses] were clever animals but I had no idea of their real genius, of their ability to think on their "feet", to assess situations, to do geometry and mapping and to develop trust and curiosity in a human being. At first it was a battle between curiosity and fear, and fear was the overriding one. Then curiosity gained the upper hand and was replaced by trust."

For Foster, this development of trust and curiosity is the central hallmark of intelligence but he admits we have a long way to go towards understanding what octopuses are actually thinking:

"Octopus thinking is so different from mammalian thinking. Much of the cognition is decentralized. She was certainly interested in me and perhaps found our interactions very stimulating, but what she actually thought is a mystery to me."

For Foster, however, the transformative impact of this intimate interaction is undeniably profound and even spiritual:

"I became sensitized to [other] animals" lives through her. Being let into her secret world, I realized just how complex and precious every animal's life is. I derived an enormous amount of curiosity and love through seeing these intricate lives, and the even more intricate webs that connect them all."

This interaction provides an avenue for reweaving the relationship with his own son by giving Foster an opportunity to teach him wild language as they free-dive together.

The second film, The Octopus in My House, follows an Alaska Pacific University marine biologist, David Scheel, as he sets up a large tank in his home to accommodate a day octopus, Octopus cyanea. The tank occupies a sizeable portion of his living room and once the octopus is comfortably ensconced, he and his daughter, Laurel, are free to observe their eight-legged tenant at their leisure. They welcome and interact with the cephalopod in myriad activities, naming her Heidi because she at first hides herself away. As she becomes more comfortable with her new surroundings, she begins to interact with her roommates. In one of many memorable scenes, we the film-viewers, find ourselves watching the threesome attentively watching television where another natural history documentary is being narrated by David Attenborough. 
One of the most intriguing behaviors recorded during The Octopus in My House, however, occurs while Heidi is sleeping. With eyes shut yet twitching, she cycles her entire body through an impressive array of eye-popping color and textural changes. When awake, octopuses are masters at camouflage. One species averaged 177 costume changes in a single hour during normal day-to-day activities according to research conducted by Roger Hanlon of the Marine Biological Laboratory in Woods Hole, Massachusetts (Hanlon \& Messenger 2018). Seeing Heidi undergoing such changes during sleep prompts Scheel to infer that perhaps Heidi is dreaming. Other scientists are more circumspect; Hanlon, William Gilly from Stanford University, and Mike Vecchione from the Smithsonian all warn that the lack of hard evidence makes it difficult to support claims of dreaming (Bugol, 2019).

For obvious experimental reasons, the act of dreaming is challenging to study in non-verbal, nonhuman animals. Certain correlated behaviors can, however, provide clues. For example, dreaming is widely thought to take place primarily during the rapid-eye movement (REM) stage of sleep (Note that dreaming has also been recorded during non-REM sleep although less commonly; Siclari et al. 2017.) Interestingly, all land mammals studied thus far from rats (Rattus sp.) to platypus (Ornithorhynchus anatinus), as well as birds, from pigeons (Columba sp. to penguins Aptenodytes patagonicus), and some non-avian reptiles e.g., bearded dragon lizards (Pogona vitticeps) engage in REM sleep (Blumberg et al. 2020, Libourel et al. 2018; Shein-Idelson et al. 2016). Different phases of sleep have been reported in a cephalopod cousin of Octopus cyanea--the common European cuttlefish (Sepia officinalis) (Iglesias et al. 2019). Whether they have a true REM-like stage remains unclear as invertebrate sleep studies are still in their infancy. We may never know for sure whether Scheel's Heidi was dreaming but capturing such behaviors on film exposes a more complex picture of octopus life and provides data inspiring increasingly intriguing hypotheses.

This is especially true for questions of comparative cognition. Octopuses diverged from our vertebrate lineage more than 550 million years ago and are the only invertebrates named in the Cambridge Declaration of Consciousness (Low et al., 2012). They have the largest and most centralized nervous system of all invertebrates, and a brain to body size ratio larger than that of most fish and reptiles (Packard, 1972, 2019; Nixon \& Young, 2003). They recognize individuals, navigate mazes, learn quickly through trial and error and display immense behavioral flexibility-an important index of cognitive capacity. Understanding how their cognition emerges through so vastly different an evolutionary pathway and deciphering the selective pressures at work casts some light on our own cognition. It also helps us develop and test new hypotheses or at least expose subtleties that may have been overlooked.

The two leading hypotheses about how cognition evolved in vertebrates are the Ecological Intelligence Hypothesis, according to which cognition emerges in response to physical environmental demands, and the Social Intelligence Hypothesis, according to which cognition emerges from the challenges of living in a complex social group (Byrne \& Whiten 1988; Dunbar 1998; Rosati 2017). Cephalopods provide a unique perspective for exploring the origins of intelligence (Amodio et al. 2018) because they are believed to have evolved in relatively simple social environments that did not require overcoming many social pressures (Boal 2006; Schnell \& Clayton 2019). Modern octopuses with their short lifespans show no evidence of providing or receiving post-hatching parental care (Hanlon \& Messenger, 2018); and in captivity they are often cannibalistic. All these features would seem to counter their capacity for cooperative behaviors (Schnell \& Clayton, 2019). With their soft vulnerable bodies and live-fast/die-young lifestyle they certainly seem to have plenty of physical environmental pressures on them to support the Ecological Intelligence Hypothesis.

Foster and Scheel, however, report some intriguing observations on octopus sociality. As Foster recounts:

"I wouldn't say I saw social behavior as such but I did see lots of tolerance and various things that made me believe that octopus are not as anti-social as they are made out to be. Some of them lived very, very close to one another, and clearly chose to do so, even though this 
environment provides many, many options for den sites. I saw physical encounters between different sized animals, but they were not violent, neither were they tender. I never saw an octopus cause another octopus harm, although I have read accounts of rare cannibalism."

In The Octopus in My House, Scheel recounts his observations of octopus aggregations in Jervis Bay, Eastern Australia-a place he dubs Octopolis. More recently, he has also documented another smaller aggregation in Jervis Bay he calls Octlantis (Scheel et al. 2017). In both these places, dozens of gloomy octopus, Octopus tetricus, engage in complex social interactions, including signaling, mating, mate defense, evacuation and eviction from dens. How anomalous such social aggregations are remains to be seen, but time and technology are affording more and more humans the kind of intimate contact needed to collect such observations.

Perhaps octopus are not as asocial as previously believed: The environmental and social explanations of the emergence of intelligence may not be mutually exclusive. Scheel (2018) argues that octopuses recognize discrete categories of agents (prey, predator and mates) and can recognize finer distinctions within each of those categories:

It's not so surprising Heidi can form a relationship with a particular category of animal in her environment-in this case her caretakers. The basic skills, the conceptual categories associated with values and expectations, are already present, along with individual recognition. It would be odd if relationships didn't follow [so that these] animals can be capable of interacting with others 'socially' when circumstances demand.

The understanding of cephalopod intelligence (and emotions) is still in early days but the increasingly sophisticated laboratory experiments on the cognition of cephalopods described by Mather (2019), Schnell \& Vallortigara (2019) and Schnell et al. (2020) are beginning to sort out the many variables that may be influencing their behavior. Such laboratory work, along with naturalistic observations in the wild like those of Foster, as well as home studies like those of Scheel and other careful researchers (e.g. Hanlon \& Messenger, 2018), will help place findings in a broader environmental context.

These two remarkable films also show the transformative power of forming meaningful relationships with other species (Louv 2005, 2019). Over the course of "seeing" and getting to know the octopus in their house, Scheel ends up rebuilding his relationship with his own daughter. The same occurs with Foster and his son, accompanied by an additional transformation:

"My experience underwater looking into octopus and shark eyes close-up has sometimes been frightening, because at first, I see the beauty of the human spirit reflected, but then I see the horror that we have unleashed on nature. I see my role in that horror as I've supported companies and products that have wreaked havoc. I now realize that biodiversity and healthy ecosystems are the life support systems of our planet, of all humans. So when I look into nature's mirror, it's deeply disturbing, but I also see deep hope in parts of the reflections and I know it's possible to regenerate this wondrous grace of wild Nature."

For Foster, the significance of this relationship extends far beyond that with a single species:

"I felt closer to early humans who once walked these shores and survived by knowing the ways of so many species. The bonds and understandings that humans have had with multiple species for so long have a profound effect on the human psyche. They make us feel like we belong. It's very satisfying to feel you belong on your own planet." 


\section{References}

Amodio, P., Boeckle, M., Schnell, A.E., Ostojic, L., Fiorito G., \& Clayton, N.S. (2018). Grow smart and die young: why did cephalopods evolve intelligence? Trends in Ecology and Evolution, 34,1, 45-56.

Blumberg M.S., Lesku, J.A., Libourel, P-A., Schmidt, M.H., \& Rattenborg, N.C. (2020). What is REM sleep? Current Biology 30: R38-R49.

Boal, J. G. (2006). Social recognition: a top down view of cephalopod behaviour. Vie et Milieu, 56, 6979.

Bugol, C. (2019). Heidi, the snoozing octopus may not be dreaming after all, Smithsonian Magazine.

Byrne, R. W. \& Whiten, A. (1988). Machiavellian Intelligence: Social Expertise and the Evolution of Intellect in Monkeys, Apes and Humans. Oxford University Press, Oxford.

Dunbar, R.I.M. (1988). The Social Brain Hypothesis. Evolutionary Anthropology, 9,178-190.

Hanlon, R.T. \& Messenger, J.B. (2018). Cephalopod Behaviour, Second Edition. Cambridge University Press, Cambridge.

Iglesias, T.L., Boal, J.G., Frank, M. G., Zeil, J. \& Hanlon, R.T. (2019). Cyclic nature of the REM sleep-like state in the cuttlefish Sepia officinalis, Journal of Experimental Biology, 222, jeb174862

Libourel, P.A., Barrillot, B., Arthaud, S., Massot, B., Morel, A. L., Beuf, O., Herrel, A., \& Luppi, P-H. (2018). Partial homologies between sleep states in lizards, mammals, and birds suggest a complex evolution of sleep states in amniotes, PLOS Biology, e2005982

Louv, R. 2008. Last Child in the World: Saving Our Children from Nature Deficit Disorder, Algonquin Books

Louv, R. 2019. Our Wild Calling: How Connecting with Animals Can Transform Our Lives and Save Theirs, Algonquin Books.

Low, P., Edelman, D. \& Koch. C. (2012). Cambridge declaration on consciousness. Paper presented at the Francis Crick Memorial Conference on Consciousness in Human and non-Human Animals, Churchill College, University of Cambridge, July 2010.

Mather, J. (2019). What is in an octopus's mind? Animal Sentience 26(1).

Nixon, M. \& Young, J.Z. (2003). The Brains and Lives of Cephalopods. Oxford University Press, Oxford. Packard, A. (1972). Cephalopod and fish: the limit of convergence. Biological Reviews, 47, 241- 301.

Packard, Andrew (2019) Keeping hold of Nurse. Animal Sentience 26(21)

Rosati, A. G. (2017). Foraging cognition: reviving the ecological intelligence hypothesis. Trends in Cognitive Sciences, 21, 691- 702.

Scheel, D., Chancellor, S., Hing, M., Lawrence, M., Linquist, S. \& Godfrey-Smith, P. (2017). A second site occupied by Octopus tetricus at high densities, with notes on their ecology and behavior. Marine and Freshwater Behaviour and Physiology, 285-291

Scheel, D. (2018). Octopuses in wild and domestic relationships, Social Science Information, 57(3), 403-421

Schnell, A. K. \& Clayton, N.S. (2019). Cephalopod cognition. Current Biology, 29, R726- R732.

Schnell, A. K. \& Vallortigara, G. (2019). 'Mind' is an ill-defined concept: considerations for future cephalopod research. Animal Sentience, 26(16).

Schnell, A. K., Amodio, P., Boeckle, M. \& Clayton, N.S. (2020). How intelligent is a cephalopod? Lessons from comparative cognition, Biological Reviews (in press)

Shein-Idelson, M., Ondracek, J.M., Liaw, H-P., Reiter, S. \& Laurent, G. (2016). Slow waves, sharp waves, ripples, and REM in sleeping dragons. Science, 352, 6285, 590-595

Siclari, F., Baird, B., Perogamvros, L., Bernardi, G., LaRocque, J. J., Riedner, B., ... \& Tononi, G. (2017). The neural correlates of dreaming. Nature Neuroscience, 20(6), 872. 